\title{
Increased Heart Rate Variability following Elective Percutaneous Coronary Intervention in Patients with Stable Coronary Artery Disease and Preprocedural Anxiety
}

\author{
Tessa Oktaramdani $\mathbb{D}^{1},{ }^{1}$ E. Mudjaddid, ${ }^{2}$ Muhadi, $^{3}$ and Hamzah Shatri ${ }^{2}$ \\ ${ }^{1}$ Department of Internal Medicine, Faculty of Medicine Universitas Indonesia-Cipto Mangunkusumo Hospital, \\ Jakarta, Indonesia \\ ${ }^{2}$ Division of Psychosomatic Medicine, Faculty of Medicine Universitas Indonesia-Cipto Mangunkusumo Hospital, \\ Jakarta, Indonesia \\ ${ }^{3}$ Division of Cardiology, Faculty of Medicine Universitas Indonesia-Cipto Mangunkusumo Hospital, Jakarta, Indonesia \\ Correspondence should be addressed to Tessa Oktaramdani; oktaramdani@gmail.com
}

Received 3 September 2019; Revised 7 November 2019; Accepted 29 November 2019; Published 20 December 2019

Academic Editor: Robert Chen

Copyright (c) 2019 Tessa Oktaramdani et al. This is an open access article distributed under the Creative Commons Attribution License, which permits unrestricted use, distribution, and reproduction in any medium, provided the original work is properly cited.

Background. There is a strong association between chronic ischemia and autonomic imbalance. Percutaneous coronary intervention (PCI) may restore autonomic balance in patients with stable coronary artery disease (SCAD), which is characterized by increased heart rate variability (HRV). Anxiety is often found in patients who are going to undergo invasive procedures and has been identified to induce autonomic imbalance. The aim of our study is to identify the impact of preprocedural anxiety on increased HRV following an elective PCI. Methods. Our study was a pretest and post-test correlation study involving 44 SCAD patients who underwent elective PCI at Cipto Mangunkusumo National Hospital. The HRV was measured before and after PCI. Anxiety symptoms were evaluated using Hospital Anxiety Depression Score (HADS) questionnaires. Results. We found a higher increase on HRV parameter following the PCI of subjects in the nonanxiety group compared with the anxiety group (median $=9.11$ vs. $2.83 ; U=154.00 ; p=0.043$ ). Conclusions. Preprocedural anxiety may inhibit HRV increase following PCI procedure.

\section{Introduction}

Autonomic dysfunction may precipitate several cardiac conditions such as arrhythmias, heart failure, and even sudden cardiac death [1, 2]. Analyzing the autonomic function allow us to predict morbidity and mortality of cardiac patients. Autonomic activity can be assessed using a noninvasive method by analyzing heart rate variability (HRV). Reduced HRV is associated with decreased cardiac flexibility and resistance to stress, which increase the risks of cardiac events. Previous studies by Gomes et al. [3]; Abrootan et al. [4]; and Aydinlar et al. [5] revealed that restoring myocardial perfusion using percutaneous coronary intervention (PCI) may improve autonomic balance, which is characterized by increased HRV.

Preprocedural anxiety is common in patients undergoing any invasive medical procedures, including PCI. Study showed that pre-PCI anxiety was detected in almost $70 \%$ of patients who underwent the procedure [6]. Anxiety may induce sympathetic hyperactivity as characterized by reduced HRV. The aim of our study was to analyze the impact of preprocedural anxiety on HRV increase following PCI.

\section{Methods}

A pretest and post-test correlation study involving 44 patients with stable coronary artery disease (SCAD) who underwent elective PCI at Integrated Heart Service Unit, Cipto Mangunkusumo National Hospital, Jakarta, was conducted between May and June 2018. Patient selection was carried out using a consecutive method with the following inclusion criteria: patients with age $\geq 18$ years, normal sinus rhythm, and chronic stable angina with significant stenosis $(\geq 50 \%)$ based on angiography examination. 
Patients with acute myocardial infarction, any need for emergent CABG after PCI, taking antiarrhythmic (except beta-blockers) drugs, antianxiety drugs, and antidepressant drugs, having a history of stroke, those with permanent brain injury, asthma, and excessive alcohol consumption $(\geq 5$ glasses/day for 5 days or more in the last 1 month), and patients with Hospital Anxiety Depression Score (HADS) $\geq 8$ on depression subscale were excluded from the study.

Education level was defined as low-intermediate for elementary-high school graduates and high level for college graduates. Occupation was defined as employee (public and private company), professional (business, medical, and law), retired, and unemployed.

Atherosclerosis risk factors were defined as follows: hypertension was defined as taking antihypertensive drugs and diabetes mellitus was defined as taking hypoglycemic agents. Stable angina was carefully obtained through medical history in most patients. Noninvasive stress tests were done in 9 subjects $(21 \%)$ with no history of PCI. Coronary stenosis was quantified by visual judgment and TIMI flow grade. Out of 44 subjects undergoing PCI, 23 subjects had full revascularization.

Standard 12-lead ECG and short-term HRV (5-minutes) measurement were performed before PCI and the next day after PCI in the morning using a photoplethysmograph analyzer. Both time domain (standard deviation of normal-tonormal intervals/SDNN; root mean square of the successive differences/RMSSD) and frequency domain (total power/TP; low frequency/LF; high frequency/HF; and LF-HF ratio) parameters were measured to be included in the study.

The Hospital Anxiety Depression Score (HADS) questionnaire was used to assess preprocedural anxiety [7, 8]. It contains 14 multiple-choice questions, divided into two subscales: anxiety and depression. Each consists of seven items, and each item has a score ranging from zero to three. Subjects with anxiety score of $\geq 8$ were classified as case.

The research protocol for our study had already been approved by the Medical Research Ethics Committee Faculty of Medicine Universitas Indonesia/Cipto Mangunkusumo Hospital, and eligible subjects had given their written consent before they were included in the study. All data were processed and analyzed using Statistical Package for the Social Sciences (SPSS) program version 20.0 for Windows.

\section{Results}

Our study population was 44 patients, which consisted of 34 $(77.3 \%)$ men and $10(22.7 \%)$ women with a mean age of $62.2 \pm 6.9$ years. There were $40(90.9 \%)$ subjects with hypertension; while 21 (47.7\%) subjects had diabetes, which is a traditional risk factor of CAD. Both conditions were wellcontrolled by antihypertension, oral antidiabetic drugs, and insulin. The baseline characteristics of our study population are summarized in Table 1.

Subjects were divided into two categories based on the result of HADS anxiety subscales, which were noncase (0-7) and case (8-21) subjects as can be seen in Table 2. The HRV parameters were measured before and after PCI and presented in Table 3. Increased HRV parameters (SDNN)
TABLE 1: Subject characteristics.

\begin{tabular}{lc}
\hline Characteristics & $n=44$ \\
\hline Age, means (SD) & $62.2(6.9)$ \\
\hline Sex, $n$ (\%) & $34(77.3)$ \\
$\quad$ Male & $10(22.7)$ \\
$\quad$ Female & $19(43.2)$ \\
\hline Education level, $n(\%)$ & $25(56.8)$ \\
$\quad$ Low-intermediate & \\
$\quad$ High & $6(13.6)$ \\
Occupation, $n(\%)$ & $20(45.5)$ \\
$\quad$ Employee & $6(13.6)$ \\
$\quad$ Professional & $12(27.3)$ \\
$\quad$ Retired & \\
$\quad$ Unemployed & $35(79.5)$ \\
\hline History of revascularization (PCI), $n(\%)$ & $9(20.5)$ \\
$\quad$ Yes & $4(9.1)$ \\
$\quad$ No & $40(90.9)$ \\
\hline Coronary artery involvement, $n(\%)$ & $21(47.7)$ \\
$\quad$ Single vessel disease & $40(90.9)$ \\
$\quad$ Multiple vessel disease & $5(11.4)$ \\
\hline Diabetes, $n(\%)$ &
\end{tabular}

TABle 2: Proportion of anxiety in patients undergoing PCI.

\begin{tabular}{lc}
\hline & $n(\%)$ \\
\hline Nonanxiety & $20(45.5)$ \\
Anxiety & $24(54.5)$ \\
\hline
\end{tabular}

following PCI in both anxiety and nonanxiety groups were compared and analyzed as presented in Table 4 .

\section{Discussion}

The characteristics of study participants regarding gender resemble those explained in previous studies of people with SCAD [9-11], in which male subjects are more frequently exposed to major risk factors such as smoking and hypertension. Out of 44 SCAD subjects undergoing elective PCI, 24 subjects (54.5\%) experienced preprocedural anxiety. Our finding is consistent with results of previous studies, which demonstrates that more than half patients undergoing PCI experience anxiety $[6,12,13]$.

Although $80 \%$ of our subjects had a history of PCI, more than half still experienced anxiety throughout the study. Studies by Trotter et al. [6] and Delewi et al. [13] showed no differences in anxiety prevalence between patients who had previous PCI with those who had PCI for the first time.

We have 21 subjects with diabetes, 11 (52\%) from the nonanxiety group and 10 (48\%) from the anxiety group. There are also 40 subjects (91\%) who had hypertension. Since high blood pressure and poor glycemic control is associated with reduced $H R V$, all hypertensive and diabetic subjects included in our study must be in optimal blood pressure and glycemic control (blood pressure $<140 / 90 \mathrm{mmHg}$, fasting plasma glucose $<130 \mathrm{mg} / \mathrm{dL}$, and post prandial plasma glucose $<180 \mathrm{mg} / \mathrm{dL}$, or $\mathrm{HbA1C}<7.5 \%)[14,15]$. 
TABLE 3: Comparison of HRV before and after PCI.

\begin{tabular}{|c|c|c|c|c|c|c|}
\hline \multirow{2}{*}{ Parameters } & \multicolumn{2}{|c|}{ Nonanxiety $(n=20)$} & \multirow{2}{*}{$p$ value } & \multicolumn{2}{|c|}{ Anxiety $(n=24)$} & \multirow{2}{*}{$p$ value } \\
\hline & Pre-PCI & Post-PCI & & Pre-PCI & Post-PCI & \\
\hline SI & $07 \quad 45$ & 1748 & 000 & $9(1587-4$ & $98(1280-50$ & 4 \\
\hline & $21.90(10.02-52.40)$ & $30.99(1$ & & $3(10.81-$ & 20.96 & .753 \\
\hline $\mathrm{TP}\left(\mathrm{ms}^{2}\right)$, median (min-max) & $523.61(178.9-1301.35)$ & $550.05(95.47-15092.0)$ & 0.232 & $492.15(208.1-1850.71)$ & $594.64(105.33-3904.3)$ & 0.607 \\
\hline $\mathrm{LF}\left(\mathrm{ms}^{2}\right)$, median $(\min -\max )$ & $107.21(3.66-1011.58)$ & $101.98(3.31-1357.97)$ & 0.391 & $83.71(6.35-1084.33)$ & $134.02(7.93-512.83)$ & 0.797 \\
\hline $\mathrm{HF}\left(\mathrm{ms}^{2}\right)$, median (min-max) & $93.91(3.57-366.56)$ & $130.64(6.63-428.78)$ & 0.167 & $155.40(6.81-998.93)$ & $83.27(5.92-1533.92)$ & 0.648 \\
\hline LF/HF, median (min-max) & $1.35(0.27-8.76)$ & $1.62(0.16-9.31)$ & 0.940 & $1.07(0.09-7.88)$ & $1.28(0.15-6.02)$ & 0.067 \\
\hline
\end{tabular}

$\mathrm{SDNN}=$ standard deviation of all normal-normal intervals; RMSSD = root mean square of the successive differences; $\mathrm{TP}=$ total power; $\mathrm{LF}=$ low frequency; $\mathrm{HF}=$ high frequency; $\mathrm{LF} / \mathrm{HF}=$ ratio $\mathrm{LF}: \mathrm{HF}$.

TABLE 4: Increased SDNN following elective PCI.

\begin{tabular}{lccc}
\hline SDNN increase (pre-post PCI) & Nonanxiety $(n=20)$ & Anxiety $(n=24)$ & $p$ value \\
\hline$\triangle$ SDNN median (min-max) & $9.11(-5.19-70.40)$ & $2.83(-18.90-33.19)$ & 0.043 \\
\hline
\end{tabular}

Eliminating ischemia through PCI can reduce central sympathetic activity, which may serve as the main source of autonomic imbalance in patients with SCAD. Therefore, coronary revascularization may restore autonomic balance, which is characterized by increased heart rate variability towards an optimal level. Previous studies have reported that SDNN of $<50 \mathrm{~ms}$ is associated with higher morbidity and mortality of cardiac patients, while patients with RMSSD $>20 \mathrm{~ms}, \mathrm{TP}>1000 \mathrm{~ms}^{2}$, and $\mathrm{LF} / \mathrm{HF}$ ratio of 1.5 to 2 are classified as healthy subjects $[16,17]$.

SDNN is the standard parameter for medical stratification of cardiac risks. It correlates with both morbidity and mortality of cardiac patients $[16,17]$ Our study revealed that the increase of SDNN following PCI is significantly higher in subjects without preprocedural anxiety compared with those with anxiety (median $=9.11$ vs. $2.83 ; U=154.00 ; p=0.043$ ). Acute anxiety triggered by acute stress could create a state of sympathetic hyperactivity, which is a condition that might hamper HRV increase even after successful revascularization [18, 19].

The limitation of our study may be the small number of the patients. As a result, designing a larger study with more cases could be more informative. Simple interventions such as psychoeducation and psychopharmacology may relieve anxiety and also prevent acute anxiety from becoming a chronic long-standing condition. Harkness et al. [20] explained that psychoeducation can improve the quality of life, angina symptoms, satisfaction level, and disease perception of SCAD patients waiting for elective catheterization. It remains to be determined whether the approach can optimize cardiac autonomic improvement following PCI.

\section{Conclusion}

Preprocedural anxiety may inhibit optimal HRV increase in SCAD patients following elective PCI. Treatment studies should be carried out to determine the impact of anxiety treatment on post-PCI HRV improvement.

\section{Data Availability}

The HRV data used to support the findings of this study are available from the corresponding author upon request.

\section{Conflicts of Interest}

The authors declare that they have no conflicts of interest.

\section{Acknowledgments}

This work was supported by the grants for International Publication of Indonesian University 2018 (Hibah Publikasi Internasional Terindeks Untuk Tugas Akhir Mahasiswa Univesitas Indonesia 2018).

\section{References}

[1] M. Vaseghi and K. Shivkumar, "The role of the autonomic nervous system in sudden cardiac death," Progress in Cardiovascular Diseases, vol. 50, no. 6, pp. 404-419, 2008.

[2] M. Omerbegovic, "Analysis of heart rate variability and clinical implications," Medical Archives, vol. 63, no. 2, pp. 102-105, 2009.

[3] M. E. Gomes, W. R. Aengevaeren, J. W. Lenders, F. W. Verheugt, P. Smits, and C. J. Tack, "Improving myocardial perfusion by percutaneous coronary intervention reduces central sympathetic activity in stable angina," Clinical Cardiology, vol. 33, no. 6, pp. E16-E21, 2010.

[4] S. Abrootan, S. Yazdankhah, B. Payami, and M. Alasti, "Changes in heart rate variability parameters after elective percutaneous coronary intervention," The Journal of Tehran University Heart Center, vol. 10, no. 2, pp. 80-84, 2015.

[5] A. Aydinlar, T. Sentürk, B. Ozdemïr, A. A. Kaderlï, and O. Aydin, "Effect of percutaneous transluminal coronary angioplasty on QT dispersion and heart rate variability parameters," Cardiovascular Journal of Africa, vol. 20, pp. 240-244, 2009.

[6] R. Trotter, R. Gallagher, and J. Donoghue, "Anxiety in patients undergoing percutaneous coronary interventions," Heart and Lung, vol. 40, pp. 185-192, 2009.

[7] M. Rudy, P. E. Widyadharma, and O. I. M. Andyana, Reliability Indonesian Version of the Hospital Anxiety and Depression Scale (HADS) of Stroke Patients in Sanglah General Hospital Denpasar, Udayana University, Bali, Indonesia, 2015.

[8] R. Caninsti, "Kecemasan dan depresi pada pasien gagal ginjal kronis yang menjalani terapi hemodialisis," Jurnal Psikologi Ulayat, vol. 1, pp. 207-222, 2013.

[9] F. Sanchis-Gomar, C. Perez-Quilis, R. Leischik, and A. Lucia, "Epidemiology of coronary heart disease and acute coronary 
syndrome," Annals of Translational Medicine, vol. 4, no. 13, p. 256, 2016.

[10] L. Mosca, E. Barrett-Connor, and N. K. Wenger, "Sex/gender differences in cardiovascular disease prevention," Circulation, vol. 124, no. 19, pp. 2145-2154, 2011.

[11] V. Regitz-Zagrosek, S. Oertelt-Prigione, E. Prescott et al., "Gender in cardiovascular diseases: impact on clinical manifestations, management, and outcomes," European Heart Journal, vol. 37, pp. 24-34, 2016.

[12] R. K. Furuya, E. C. A. Costa, M. Coelho et al., "Anxiety and depression among men and women who underwent percutaneous coronary intervention," Rev Esc Enferm, vol. 47, pp. 1332-1336, 2013.

[13] R. Delewi, W. Vlastra, W. J. Rohling et al., "Anxiety levels of patients undergoing coronary procedures in the catheterization laboratory," International Journal of Cardiology, vol. 228, pp. 926-930, 2016.

[14] C. N. Nganou-Gnindjio, C. M. Mba, M. Azabji-Kenfack et al., "Poor glycemic control impacts heart rate variability in patients with type 2 diabetes mellitus: a cross sectional study," BMC Research Notes, vol. 11, p. 599, 2018.

[15] M. Jaiswal, T. E. Fingerlin, E. M. Urbina et al., "Impact of glycemic control on heart rate variability in youth with type 1 diabetes: the SEARCH CVD study," Diabetes Technology \& Therapeutics, vol. 15, no. 12, pp. 977-983, 2013.

[16] F. Shaffer and J. P. Ginsberg, "An overview of heart rate variability: metrics and norms," Front Public Health, vol. 5, p. 258, 2017.

[17] A. John Camm, M. Malik, J. Thomas Bigger, Jr. et al., “Task force of the european society of cardiology the north american society of pacing electrophysiology. Heart rate variability: standards of measurement, physiological interpretation, and clinical use," Circulation, vol. 93, pp. 1043-1065, 1996.

[18] B. H. Friedman, "An autonomic flexibility-neurovisceral integration model of anxiety and cardiac vagal tone," Biological Psychology, vol. 74, no. 2, pp. 185-199, 2007.

[19] B. G. Scott and C. F. Weems, "Resting vagal tone and vagal response to stress: associations with anxiety, aggression, and perceived anxiety control among youths," Psychophysiology, vol. 51, no. 8, pp. 718-727, 2014.

[20] K. Harkness, L. Morrow, K. Smith, M. Kiczula, and H. M. Arthur, "The effect of early education on patient anxiety while waiting for elective cardiac catheterization," European Journal of Cardiovascular Nursing, vol. 2, no. 2, pp. 113-121, 2003. 


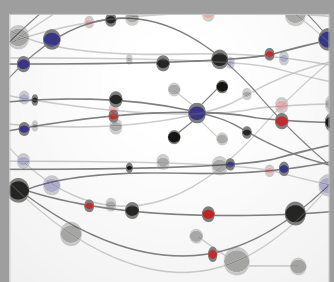

The Scientific World Journal
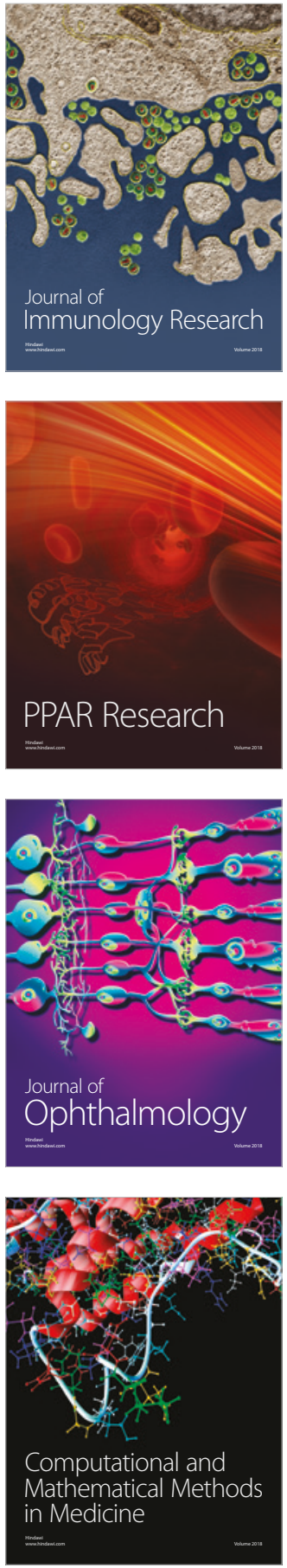

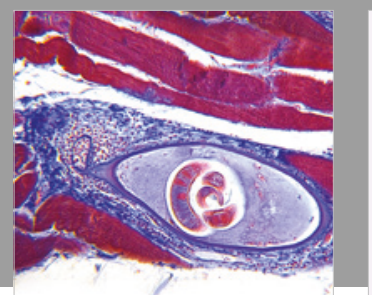

Gastroenterology Research and Practice

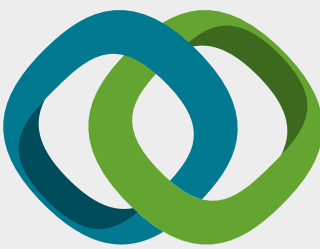

\section{Hindawi}

Submit your manuscripts at

www.hindawi.com
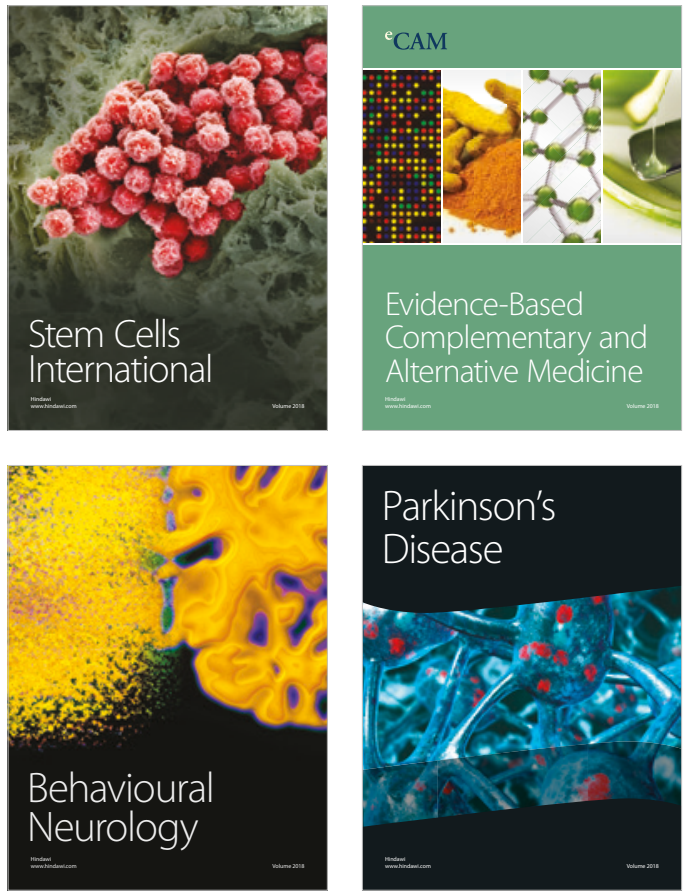

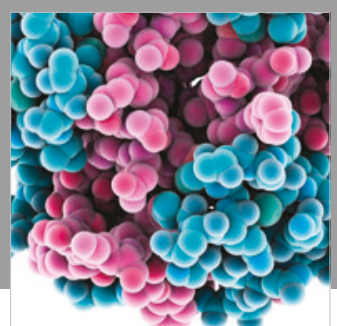

ournal of

Diabetes Research

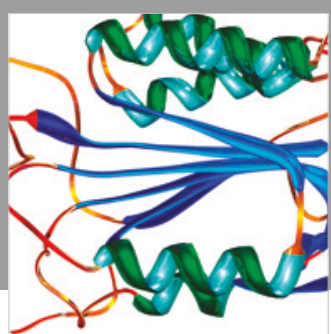

Disease Markers
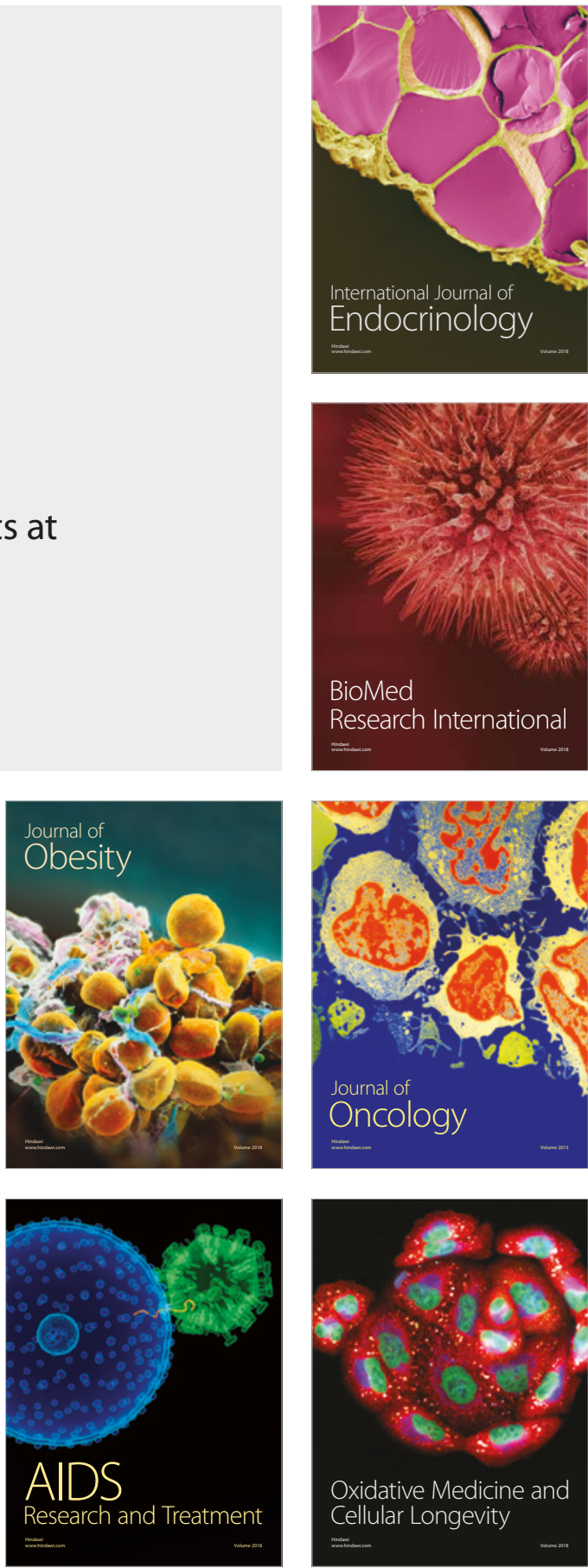